\title{
Analysis of Mercury in Skin Lightening Cream by Microwave Plasma Atomic Emission Spectroscopy (MP-AES)
}

\author{
Hardoko I. Qudus ${ }^{1, *(\mathbb{D}, \text { Purwadi Purwadi }}{ }^{2}$, Iis Holilah ${ }^{3}$ and Sutopo Hadi ${ }^{1, *(D)}$ \\ 1 Department of Chemistry, Faculty of Mathematics and Natural Sciences, Universitas Lampung, \\ Bandar Lampung 35145, Indonesia \\ 2 Indonesia National Agency of Food and Drug Control, Bandar Lampung 35228, Indonesia; \\ mutubpomlpg@gmail.com \\ 3 Public Senior High School 16, Bandar Lampung 35153, Indonesia; naisyaparis@gmail.com \\ * Correspondence: hardoko.insan@fmipa.unila.ac.id (H.I.Q.); sutopo.hadi@fmipa.unila.ac.id (S.H.); \\ Tel.: +62-811-790-460 (H.I.Q.); +62-813-6905-9733 (S.H.)
}

Citation: Qudus, H.I.; Purwadi, P.; Holilah, I.; Hadi, S. Analysis of Mercury in Skin Lightening Cream by Microwave Plasma Atomic Emission Spectroscopy (MP-AES). Molecules 2021, 26, 3130. https://doi.org/ $10.3390 /$ molecules 26113130

Academic Editor: Pawel Pohl

Received: 19 April 2021

Accepted: 21 May 2021

Published: 24 May 2021

Publisher's Note: MDPI stays neutral with regard to jurisdictional claims in published maps and institutional affiliations.

Copyright: (c) 2021 by the authors. Licensee MDPI, Basel, Switzerland. This article is an open access article distributed under the terms and conditions of the Creative Commons Attribution (CC BY) license (https:/ / creativecommons.org/licenses/by/ $4.0 /)$.

\begin{abstract}
This research aimed at developing an analysis method, which was optimized and validated to determine the content of mercury in skin lightening cream discovered in the market in Bandar Lampung, Indonesia, through the use of microwave plasma atomic emission spectroscopy (MPAES). The optimization on the analysis method was conducted on pump rate, viewing position, and reductant concentration in order to obtain the highest mercury emission intensity, while the solution stability was optimized to know the stability of mercury in the solution. The result showed that the method developed had precision with a relative standard deviation of $2.67 \%$, recovery value of $92.78 \%$, and linearity with an $r$ value of 0.993 , respectively. The sensitivity of the instrument detection had a limit of analysis method detection and quantification of 0.59 and $1.98 \mu \mathrm{g} / \mathrm{L}$, respectively. The results of the test of the lightening cream ( 8 of 16 samples) positively contained mercury in the range of $422.61-44,960.79 \mathrm{ng} / \mathrm{g}$. Therefore the method of analysis developed may be used for routine analysis of chemicals in any cosmetics products.
\end{abstract}

Keywords: analytical method validation; mercury; MP-AES; skin lightening cream

\section{Introduction}

Cosmetics are materials intended for the use on the outer human body parts such as epidermis, hair, nail, lips, outside genital organs, teeth, and on mouth mucosa membrane, as they are specifically used for cleaning up, perfuming, performance altering, and body smell fixing while protecting and accurately maintaining the body condition [1].

One of the cosmetics often used by women is skin lightening cream. Unfortunately, most of these products in the market use mercury as an added material [1-6]. This is due to the fact that mercury has the ability to whiten skin color within a relatively short time. However, this metal accumulates in the human body, especially in the kidney, liver, and brain, which in turn causes negative effects on health $[2,6]$.

Due to the high danger of mercury in cosmetics, this metal obtained high attention from the WHO, based on the adverse effect on human health [7]. A high concentration of mercury present in inorganic and organic compounds causes permanent toxicity in the brain, kidney, and embryo growth [3,4,6-8]. The poisonous level of mercury depends on its chemical form, with the lowest and highest appearances being ionic and metallic organomercury $[1,2,7]$.

Mercury is a toxic metal and non-essential in the human body. The environmental problems are mostly caused by exposure to the organic mercury compound [1,7]. The inorganic metals are also converted to organic forms by the decomposition process of sulfate bacteria, which produces methylmercury, one of the most toxic forms of mercury compounds that are easily absorbed by cell membranes. Further, methylmercury causes 
problems in the nervous system, resulting in an abnormal function of the nervous system. Chronic toxicity due to mercury includes paresthesia, neuropathy perifer, cerebellar ataxia, akathisia, spasticity, memory loss, dementia, limited sight, dysarthria, hearing problems, a decrease in smell and taste values, tremor, and depression [8].

The determination of metals or metallic pollutants is generally performed by using flame atomic absorption spectroscopy (F-AAS) [5], hydride generation AAS [9-11], cold vapor AAS [12], inductively coupled plasma mass spectrometry (ICP-MS) [13-15], and, recently, microwave plasma atomic emission spectrometry (MP-AES) has also been utilized $[14,15]$. However, the operation of some of these techniques is high in cost, for example, F-AAS uses acetylene or nitrogen oxide as burning gas with a high flow rate speed, while also using a hollow cathode lamp with a certain lifetime. In addition to that, the detection limit of F-AAS is quite high, resulting in it not being good for metal contamination. Further, ICP-MS has a good detection limit, even though the use of argon limits its uses [13].

Karlson et al. [15] compared both MP-AES and ICP-MS methods, which included low and high cost analyses with detection limits in the units of $\mu \mathrm{g} / \mathrm{L}$ and $\mathrm{ng} / \mathrm{L}$, respectively, in some metals such as $\mathrm{Mg}, \mathrm{Ca}, \mathrm{Fe}$, and $\mathrm{Al}$ obtained from sun flowers. The results obtained were not significantly different, although few metals were not detected using MP-AES.

The development of the MP-AES analysis technique began with polluted metal on a variety of matrices, as reported by Wu et al. [16] and Yang et al. [17], who analyzed the material of Chinese herbals. Further, Zhao et al. [13] determined the content of some metals, including mercury, in skin and hair. The major challenges on the analysis of mercury in cosmetics include that the organic matrices are difficult to be digested, the wide variation of mercury concentration in the cosmetics products, and the composition of mercury is not clearly mentioned on the label $[18,19]$.

MP-AES is a relatively new technique for metal analysis, which is also a metalloid in a variety of sample matrices. However, the use of this technique has not been supported with a developed analysis method, as no analytical development to analyze mercury in cosmetic cream has been performed. In this paper, the method of analysis using MP-AES to determine the content of mercury in some selected lightening creams obtained in the market in Bandar Lampung, Indonesia, was reported.

\section{Results}

The optimization of the nebulizer pressure and plasma viewing position was performed using MP-Expert software. The optimum pressure of the nebulizer was $160 \mathrm{kPa}$, with a viewing position at the zero point. Moreover, optimization was also conducted for every measurement. Using the optimum condition of the pressure nebulizer and viewing position the optimization of the pump speed was collected, in order to know the velocity at which the highest emission intention was obtained. Variations were also performed at $10,20,30,40$, and $50 \mathrm{rpm}$, as the optimum conditions were further obtained at $40 \mathrm{rpm}$, as shown in Figure 1.

The intensity of the measurement was directly proportional to the pump speed up to $40 \mathrm{rpm}$; this then dropped off at $50 \mathrm{rpm}$. However, the large pump speed resulted in a larger volume of the required test sample.

Subsequent optimization of the reductant concentration of $\mathrm{NaBH}_{4}$ was carried out at a pump speed of $40 \mathrm{rpm}$, which was conducted at variations of $0.5,1.5,2.0$, and $2.5 \%$, with optimum conditions at $1.5 \%$ of $\mathrm{NaBH}_{4}$. The results are shown in Figure 2. 


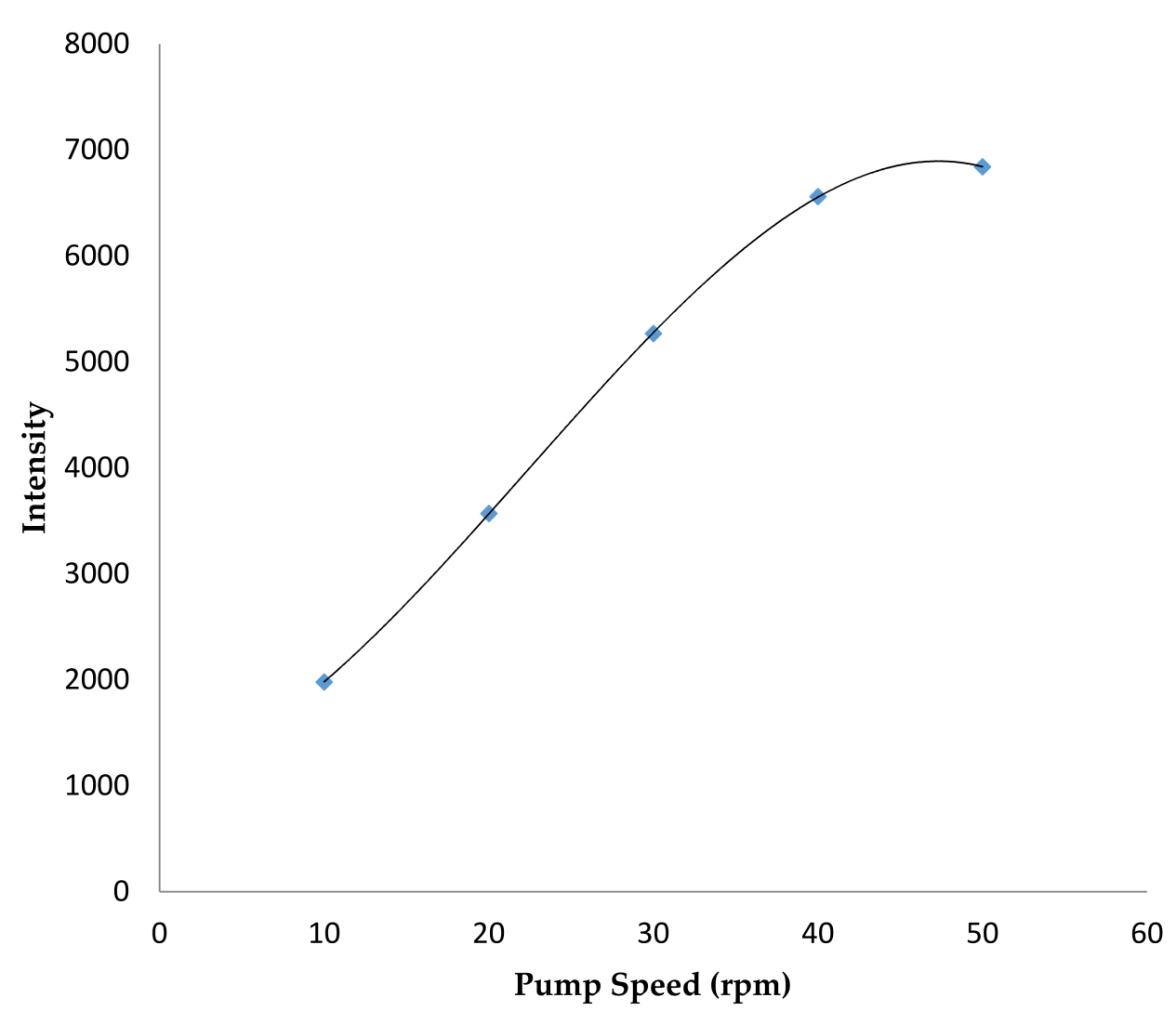

Figure 1. The effect of varying pump speed on the intensity of mercury emission at $253.652 \mathrm{~nm}$.

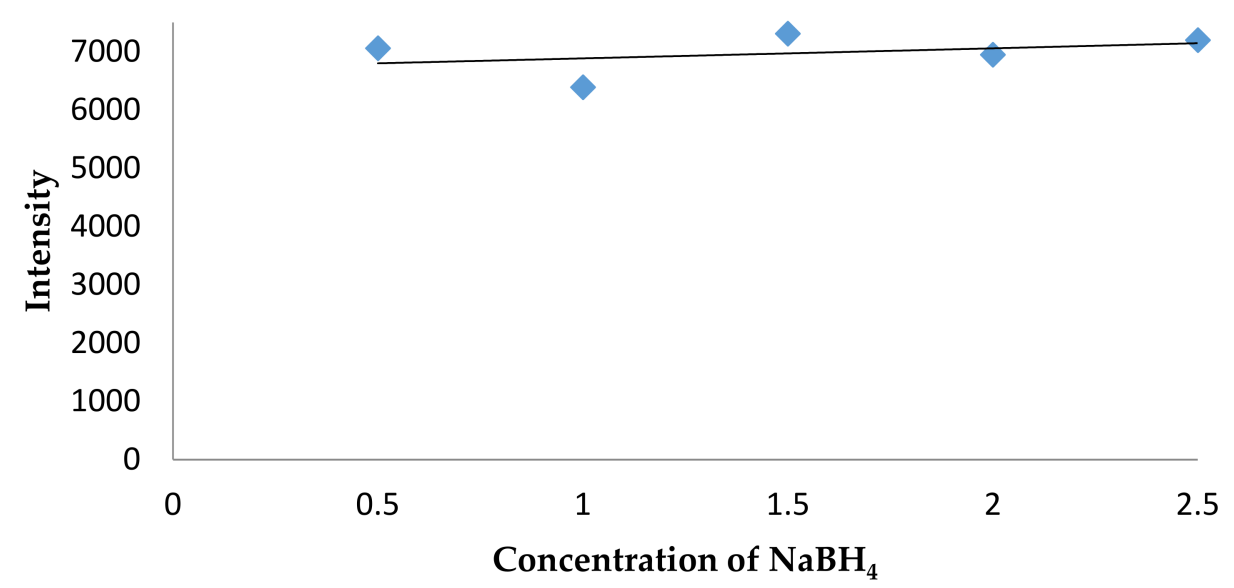

Figure 2. Optimization of $\mathrm{NaBH}_{4}$ concentration.

Figure 3 showed the stability test using a standard mercury solution of $150 \mu \mathrm{g} / \mathrm{L}$, the mercury solution in nitric acid was unstable in the first $2 \mathrm{~h}$ as shown by the intensity decrease of about $12.5 \%$; however, this solution was stable up to $7 \mathrm{~h}$, but the measurement after $7 \mathrm{~h}$ was not carried out. This change did not affect the measurement of the samples much as long as the measurement was conducted at an interval time of 2-7 h after the initial dissolving of the mercury standard and the samples. 


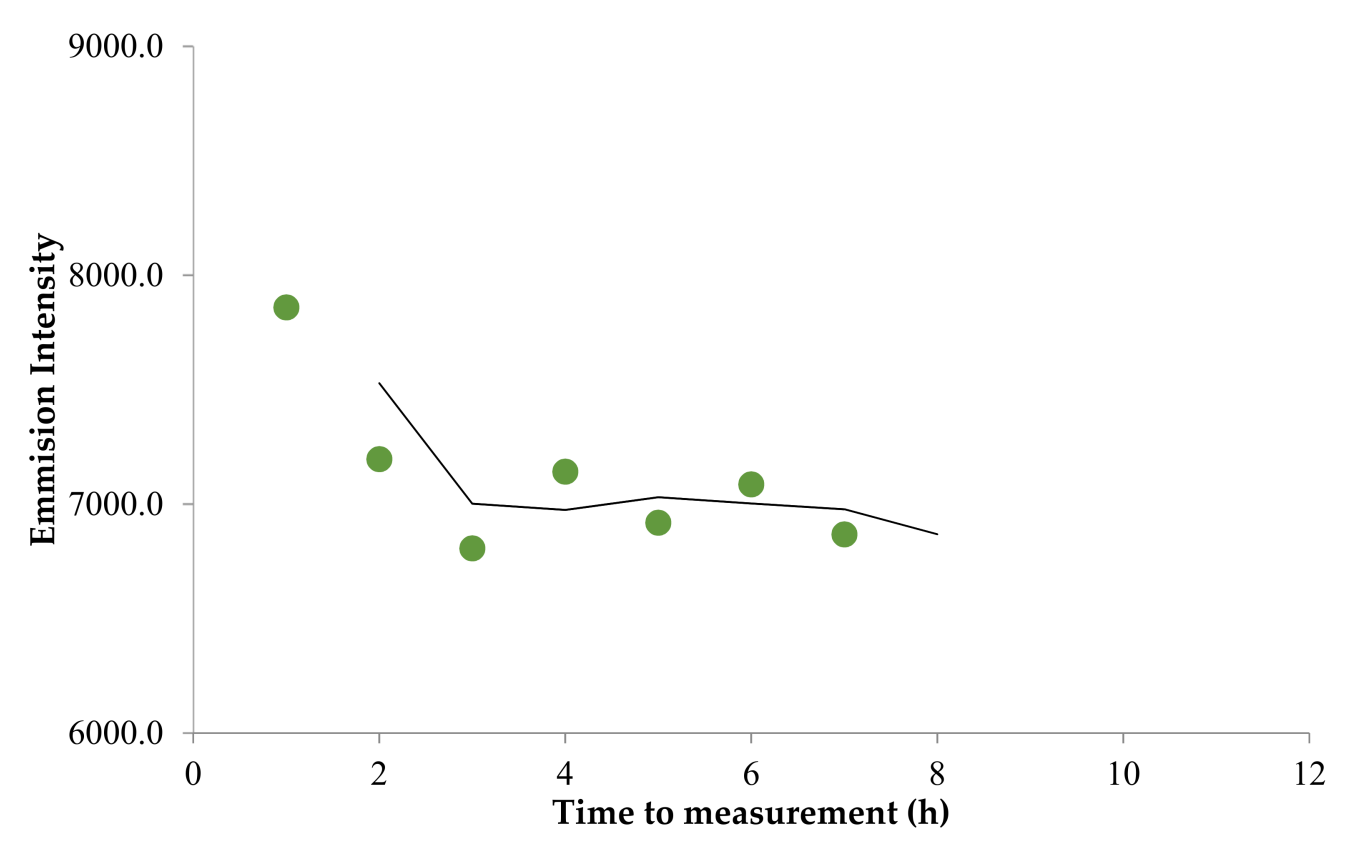

Figure 3. Stability test of the solution.

Further, the precision test result had a very good repetition, which was used with an RSD value of $2.67 \%$, as shown in Table 1 .

Table 1. Precision test of the method used.

\begin{tabular}{cc}
\hline Label & Intensity \\
\hline Precision 1 & 2118.279 \\
Precision 2 & 2071.708 \\
Precision 3 & 2040.439 \\
Precision 4 & 1993.080 \\
Precision 5 & 2005.446 \\
Precision 6 & 1973.390 \\
Average & 2033.724 \\
Standard deviation (SD) & 54.28 \\
RSD (\%) & 2.67 \\
\hline
\end{tabular}

The accuracy of the method was tested by a recovery test with the addition of mercury standard solution to the pure cream sample. The result of the accuration test method showed very high accuracy where the recovery percentage was satisfied, as shown in Table 2. The levels obtained were then calculated for the added cream sample with negative mercury, using the calibration curve equation of the standard mercury measurement of $5-90 \mu \mathrm{g} / \mathrm{L}$, as indicated in $\mathrm{y}=58.78 \mathrm{x}-147.9$.

The results of the linearity test method also showed that it was quite linear as it produced a regression equation of $y=46.87 x+277.75$ with a coefficient correlation $(r)$ of 0.993, as shown in Figure 4. The test was performed on a sample of lightening creams, which were added to mercury.

Furthermore, the method of the sensitivity test was conducted by using a serial standard mercury solution on a low concentration at 1-6 $\mu \mathrm{g} / \mathrm{L}$ (Figure 5). This method was confirmed to be very sensitive, with LoD and LoQ at 0.59 and $1.98 \mu \mathrm{g} / \mathrm{L}$, respectively.

Based on the use of the methods developed, the measurement result of the mercury content present in the sample skin lightening cream produced the following data shown in Table 3. 
Table 2. Accuration test of the method.

\begin{tabular}{ccccc}
\hline Label & Intensity & $\begin{array}{c}\text { Expected Value } \\
\text { (ng/g) }\end{array}$ & $\begin{array}{c}\text { Obtained Value } \\
\text { (ng/g) }\end{array}$ & Recovery (\%) \\
\hline Recovery 1 & 2118.279 & 40.00 & 38.55 & 96.37 \\
Recovery 2 & 2071.708 & 40.00 & 37.76 & 94.39 \\
Recovery 3 & 2040.439 & 40.00 & 37.23 & 93.06 \\
Recovery 4 & 1993.080 & 40.00 & 36.42 & 91.05 \\
Recovery 5 & 2005.446 & 40.00 & 36.63 & 91.57 \\
Recovery 6 & 1973.390 & 40.00 & 36.08 & 90.21 \\
\hline \multicolumn{4}{c}{ Average } \\
& \multicolumn{3}{c}{ The smallest } \\
\\
\multicolumn{4}{c}{ The biggest } \\
\hline
\end{tabular}

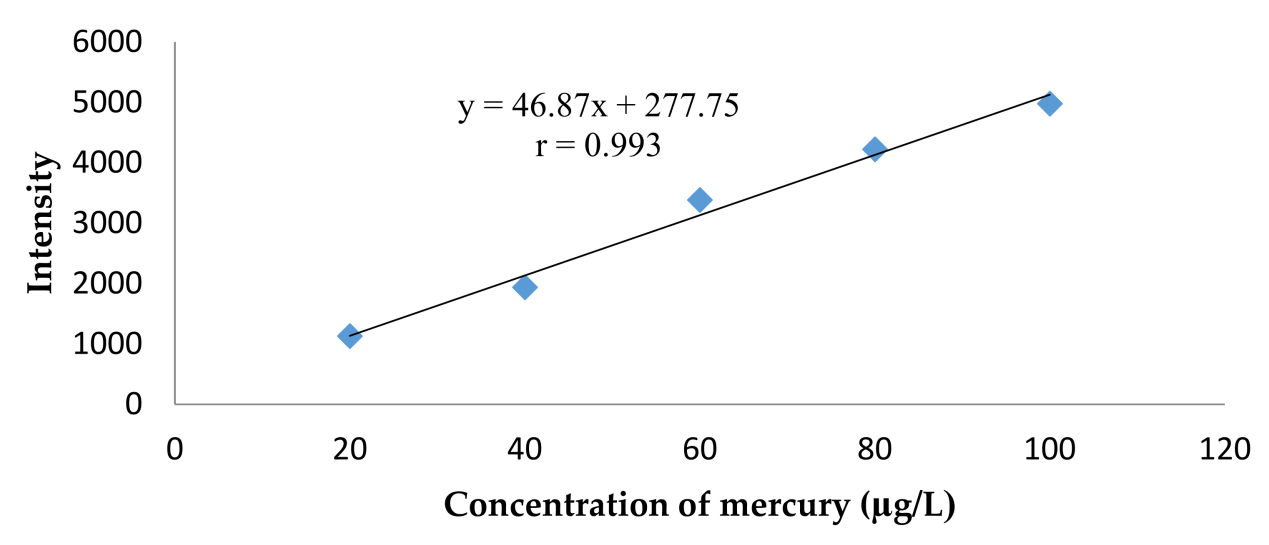

Figure 4. The result of linearity test method.

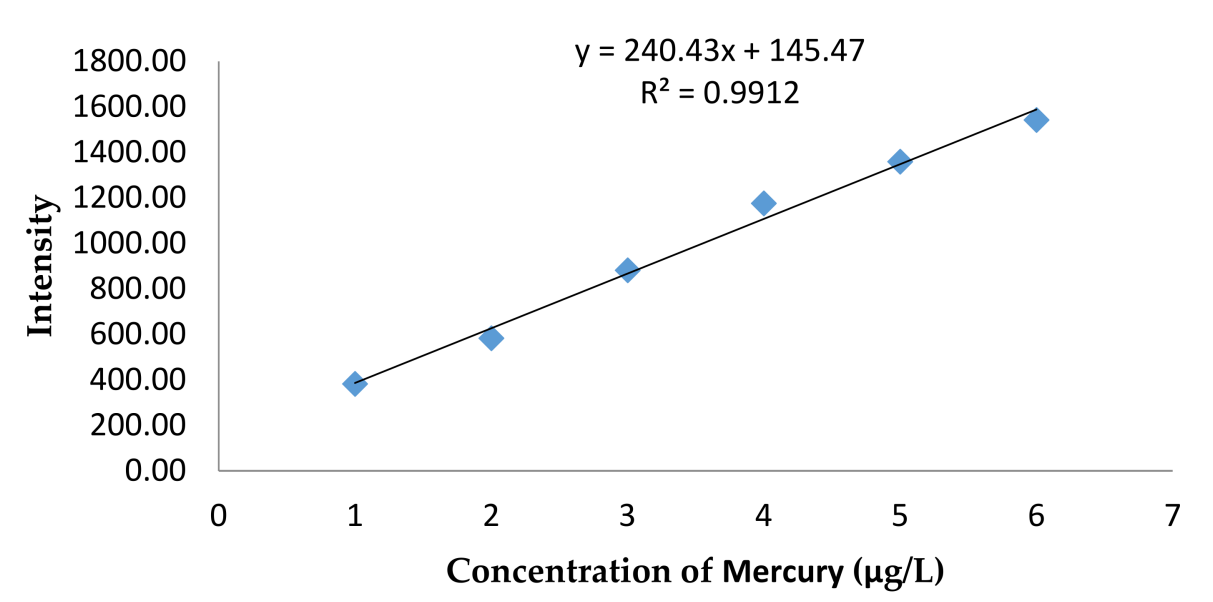

Figure 5. Calibration curve of mercury on low concentration.

Table 3. Mercury concentration in the sample measured.

\begin{tabular}{cc}
\hline Sample Code & Mercury Content $(\mu \mathrm{g} / \mathrm{g})$ \\
\hline 1 & n.d. \\
2 & n.d. \\
3 & n.d. \\
4 & n.d. \\
5 & 1901.82 \\
\hline
\end{tabular}


Table 3. Cont.

\begin{tabular}{cc}
\hline Sample Code & Mercury Content $(\mu \mathrm{g} / \mathrm{g})$ \\
\hline 6 & n.d. \\
7 & 422.61 \\
8 & n.d. \\
9 & n.d. \\
10 & n.d. \\
11 & 836.27 \\
12 & $44,960.79$ \\
13 & $26,212.56$ \\
14 & 6681.45 \\
15 & 4928.30 \\
16 & 4360.44 \\
\hline
\end{tabular}

n.d. = not detected.

\section{Discussion}

MP-AES is a relatively new analytical technique, which was developed by Agilent Technologies [16]. This analysis technique offered several advantages when juxtaposed with older analytical methods, including AAS and ICP. Some of the advantages of MPAES include low operating costs and safe usage. However, this analytical technique also revealed challenges in regard to the lack of available methods for the analysis of metals and semi-metallic elements on various matrices.

In this study, a mercury analysis was determined by MP-AES with the reaction chamber of MSIS (multimode sample introduction system), as well as the optimization results of the tool obtained by an optimum nebulizer pressure of $160 \mathrm{kPa}$, viewing position at the zero point, and pump rate of $40 \mathrm{rpm}$. The optimization of the tool was intended to obtain maximum measurement intensity and good repeatability. Further, the gas used to produce plasma was nitrogen, which was the in-situ product of the N-generator. The optimum pressure also produced maximum nebula, which was an aerosol filled with analytes. However, the view position was intended to obtain the highest intensity, which was captured by the detector.

At the optimization stage of $\mathrm{NaBH}_{4}$ (Figure 2), the optimum concentration value obtained was $1.5 \%$. The addition of this concentration aimed to convert the mercury ion into mercuric hydrides, as it became more volatile and was easily delivered to the torch after nebulization. $\mathrm{NaBH}_{4}$ was also provided in excess at this stage of the process, as it intended to change the mercury analyte perfectly both in the reference standard solution and the sample.

According to Robbins and Caruso [9], the reaction that occurred between the reductant $\mathrm{NaBH}_{4}$ with mercury, arsenic, and selenium, was shown in Equations (1) and (2), where E was the metal $\mathrm{Hg}$, As, and $\mathrm{Se}$, with the values of $\mathrm{m}$ and $\mathrm{n}$ being similar, even though they were also likely to be different.

$$
\begin{gathered}
\mathrm{NaBH}_{4}+3 \mathrm{H}_{2} \mathrm{O}+\mathrm{HCl} \rightarrow \mathrm{H}_{3} \mathrm{BO}_{3}+\mathrm{NaCl}+8 \mathrm{H}^{-} \\
\mathrm{E}^{\mathrm{m}+}+\mathrm{H}^{-} \text {(excess) } \rightarrow \mathrm{EH}_{\mathrm{n}}+\mathrm{H}_{2} \text { (excess) }
\end{gathered}
$$

Furthermore, the solution stability test (Figure 3) showed that the concentration was stable after $2 \mathrm{~h}$, and this solution was relatively stable up to $7 \mathrm{~h}$. This time span was required to be known when considering the analyst's testing habits from preparation to completion of the measurements.

The validity of this method also fulfilled the requirements with the results of the precision test, which produced a relative standard deviation of $2.67 \%$ (Table 2). Further, the requirement for analytes at a level of $10 \mathrm{ng} / \mathrm{mL}$ was $21 \%$ [20]. Moreover, the accuracy of this method was $92.78 \%$, which fulfilled the requirements for $10 \mathrm{ppb}$ of recovery, at $60-115 \%$ [20]. This accuracy test was the most important considering the fact that mercury 
analytes were volatile at high temperatures. However, this method used the digestion technique at high temperatures and pressures (Table 4).

Table 4. The condition of the sampling technique in the microwave digestion oven.

\begin{tabular}{cccc}
\hline Step & Temperature $\left({ }^{\circ} \mathbf{C}\right)$ & Time $($ min) & Power (Watt) \\
\hline 1 & 130 & 10 & 800 \\
2 & 160 & 10 & 800 \\
3 & 190 & 10 & 800 \\
\hline
\end{tabular}

This analysis method also had good linearity, as reflected in the correlation coefficient (r) of 0.991 (Figure 5). Further, the sensitivity of the method was quite good, as shown from the LoD and LoQ (limit of detection and quantification) values of 15.01 and $50.02 \mathrm{ng} / \mathrm{g}$, respectively. The measurement of mercury used a cold-vapor-AAS-produced detection limit of $0.02 \mathrm{ppm}(\mu \mathrm{g} / \mathrm{g})$ [21], while, when using ICP-MS, the detection limit obtained was $0.02 \mu \mathrm{g} / \mathrm{L}$ [22]. The obtained result in this work was $0.59 \mathrm{ng} / \mathrm{g}$. Therefore, the test results of the lightening cream cosmetic material showed that in 8 of the 16 samples analyzed indicated mercury levels within the range of $422.61-44,960.79 \mu \mathrm{g} / \mathrm{g}$. The method of analysis for mercury obtained in this work can be used and proposed for routine analysis of mercury in the cosmetics samples.

\section{Materials and Method}

\subsection{Materials}

All reagents used were of $A R$ grade. These include sodium borohydride $\left(\mathrm{NaBH}_{4}\right.$, (Merck, Kenilworth, NJ, USA), sodium hydroxide $(\mathrm{NaOH},($ Merck)), 37\% hydrochloric acid $(\mathrm{HCl},(\mathrm{Merck})), 30 \%$ hydrogen peroxide $\left(\mathrm{H}_{2} \mathrm{O}_{2},(\mathrm{Merck})\right), 65 \%$ nitric acid $\left(\mathrm{HNO}_{3},(\mathrm{Merck})\right)$, and deionized water from a Millipore purifier (Merck) with a resistance of $18.2 \mathrm{M} \Omega . \mathrm{cm}$. Additionally, the standardized reference using mercury ICP (Merck), traceable to NIST Standard Reference Material ${ }^{\circledR}(\mathrm{SRM}) \mathrm{Hg}\left(\mathrm{NO}_{3}\right)_{2}$ in $10 \%$ nitric acid, equaled $1000 \mathrm{mg} / \mathrm{L} \mathrm{Hg}$.

The samples for method validation through cosmetic materials of the lightening creams selected were not detected using optimization results. Moreover, 16 test samples were obtained from some distribution area in Bandar Lampung.

\subsection{Reagent Preparation}

The nitric acid solution used for the standard solution and the digested sample was prepared by diluting $10 \mathrm{~mL}$ of nitric acid P.A. with deionized water, up to a volume of $1 \mathrm{~L}$. Afterward, the reductant solution of sodium borohydride was gradually prepared by mixing $1.0 \% \mathrm{NaOH}$ solution into $0.5-2.5 \mathrm{~g}$ of $\mathrm{NaBH}_{4}$ until a volume of $100 \mathrm{~mL}$ was reached [23]. Further, a $100 \mu \mathrm{L}$ aliquot was obtained from the preparation of the standard mercury solution of $1000 \mathrm{mg} / \mathrm{L}$ and diluted with solvent $\mathrm{HNO}_{3}$ to a volume of $100 \mathrm{~mL}(\mathrm{Hg}$ concentration of $1.0 \mathrm{mg} / \mathrm{L})$. Afterward, the mercury series standard solution was further prepared, by serially pipetting $0.1-15.0 \mathrm{~mL}$ of the main standardized content, as each was dissolved with $100 \mathrm{~mL}$ of solvent in order to obtain a metallic concentration of $1-150 \mu \mathrm{g} / \mathrm{L}$.

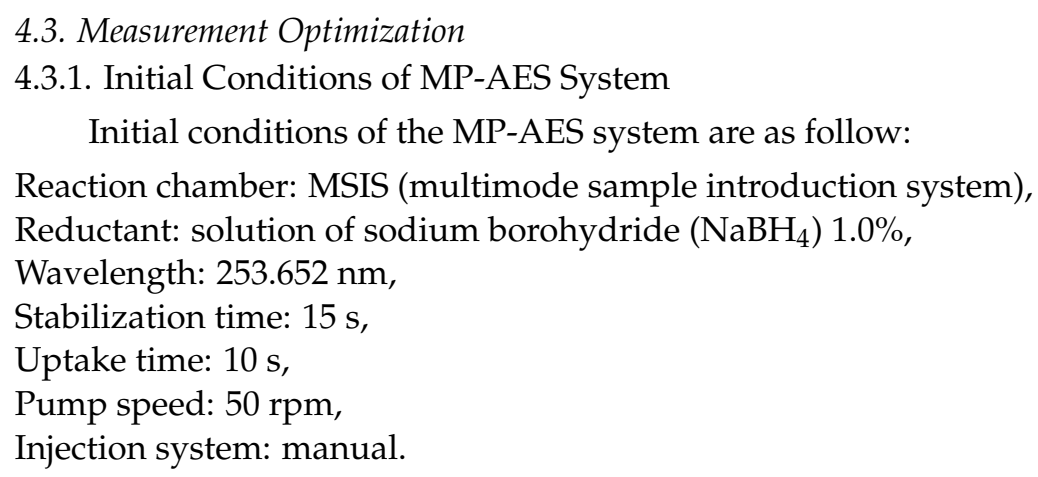


The optimization of the nebulizer pressure, viewing position, and pump speed was performed in an initial system using a standard solution of mercury at $150 \mu \mathrm{g} / \mathrm{L}$. The optimization was then carried out through the use of MP-Expert software (MP-4100, Agilent, Santa Clara, CA, USA).

\subsubsection{Optimization of $\mathrm{NaBH}_{4}$ Reductant Concentration}

The optimization of $\mathrm{NaBH}_{4}$ reductant concentration was also performed in an optimum condition, based on the previous experiments, by varying concentrations of $0.5-2.5 \%$.

\subsubsection{Test of Solution Stability}

The test of solution stability was measured with MP-AES at the optimum condition obtained from previous experiments using a standard mercury concentration of $150 \mu \mathrm{g} / \mathrm{L}$. The measurement was performed periodically from $0-7 \mathrm{~h}$ starting from the preparation of the solution stock at $1 \mathrm{~h}$.

\subsection{Sample Preparation}

The cream sample of $0.2-0.25 \mathrm{~g}$ was placed on a Teflon vessel, as 8 and $2 \mathrm{~mL}$ of nitric acid (concentrated) and $\mathrm{H}_{2} \mathrm{O}_{2}$ were added and left for $20 \mathrm{~min}$, respectively. Afterward, this was digested in a microwave digestion oven at the conditions shown in Table 4.

After being digested, the samples were dissolved with deionized water in a volumetric flask of $50 \mathrm{~mL}$, which was equipped with Whatman ${ }^{\circledR}$ Filter Paper No. 1, as the solution materials were then measured with MP-AES. If the intensity was still too high, they were further diluted.

\subsection{Precision Test}

During this test, the cream sample of $0.2-0.25 \mathrm{~g}$ was placed on the Teflon vessel, as $200 \mu \mathrm{L}$ stock solution of $10 \mathrm{mg} / \mathrm{L}$ mercury was added, with the measurement further carried out by using MP-AES. The precision test was performed six times, as the relative standard deviation was then calculated.

\subsection{Accuracy Test}

Using the result obtained with the precision test, the calculations of the recovery percentage and sample content were used with the calibration curve, which was obtained through the use of mercury concentration at 5-90 $\mu \mathrm{g} / \mathrm{L}$.

\subsection{Linearity Test}

A sample of $0.2-0.25 \mathrm{~g}$ was further placed in the vessel, and a stock mercury solution of $10 \mathrm{mg} / \mathrm{L}$ was added in the amount of $0,100,200,300,400,500$, and $600 \mu \mathrm{L}$. The measurement was then carried out using MP-AES, as the regression linear analysis was formed with the correlation coefficient ( $\mathrm{r}$ ) also being measured.

\subsection{Test of Limit of Detection (LoD) and Limit of Quantity (LoQ)}

The measurement of mercury solution stock with a concentration of $1-6 \mu \mathrm{g} / \mathrm{L}$ was performed, and the calculations of LoD and LoQ were 3 and $10 \mathrm{Sy}(\mathrm{x}) / \mathrm{b}$, respectively.

\section{Conclusions}

The result of the development analysis method of mercury on skin lightening cream through the use of MP-AES with the optimum condition of the MSIS (multimode sample introduction system) showed a wavelength with stabilization and uptake durations at $253.652 \mathrm{~nm}$ with 15 and $10 \mathrm{~s}$, respectively. Further, the introduction system, in which the manual was obtained, was the nebulizer pressure of $160 \mathrm{kPa}$, viewing position at point zero, pump rate at $40 \mathrm{rpm}$, and $\mathrm{NaBH}_{4}$ concentration at $1.5 \%$, with a duration of the test solution stability at $7 \mathrm{~h}$. Furthermore, the validation method fulfilled the requirements of the precision test, with a relative standard deviation of $2.67 \%$. The accuracy of this method, 
based on the recovery test, was also $92.78 \%$, with the linearity of the correlation coefficient at 0.993 . Further, the limits of the instrumental detection and quantitation obtained were 0.59 and $1.98 \mu \mathrm{g} / \mathrm{L}$, respectively. Moreover, the analysis method results of LoD and LoQ were 15.01 and $50.02 \mathrm{ng} / \mathrm{g}$, respectively. Therefore, out of the 16 cosmetic samples of skin lightening creams tested, 8 were detected to contain mercury, with a content range of $422.61-44,960.79 \mu \mathrm{g} / \mathrm{g}$. Therefore, in future work, it is suggested to use other solvents such as $\mathrm{HCl}$ or $\mathrm{BrCl}$, and other equivalent techniques such as $\mathrm{CV}$ AAS or ICP-MS to compare the results obtained.

Author Contributions: Conceptualization, H.I.Q. and S.H.; methodology, H.I.Q. and S.H.; software, P.P. and I.H.; validation, H.I.Q. and P.P.; investigation, H.I.Q. and I.H.; resources, I.H.; supervision, H.I.Q. and S.H.; writing—original draft preparation, H.I.Q. and S.H.; writing-review and editing, H.I.Q. and S.H.; project administration, H.I.Q. All authors have read and agreed to the published version of the manuscript.

Funding: This research received no external funding.

Institutional Review Board Statement: Not applicable.

Informed Consent Statement: Not applicable.

Data Availability Statement: The data produced from this study can be requested from the corresponding author upon reasonable request.

Acknowledgments: The authors are grateful to the Head of the Indonesian National Agency of Food and Drug Control (BP POM), Bandar Lampung, for the permission to use the laboratory in order to develop the analysis method through the use of MP-AES.

Conflicts of Interest: The authors declare no conflict of interest.

Sample Availability: Not available.

\section{References}

1. Regulation of Indonesia National Agency of Food and Drug Control (INAFDC/BPOM). The Pollutants in Cosmetics; National Agency of Food and Drug Control: Jakarta, Indonesia, 2019. (In Indonesian)

2. Clarkson, T.; Magos, L. The toxicology of mercury and its chemical compounds. Critic. Rev.Toxicol. 2006, 36, 609-662. [CrossRef] [PubMed]

3. Arshad, H.; Mehmood, M.Z.; Shah, M.S.; Abbasi, A.M. Evaluation of heavy metals in cosmetic products and their health risk assessment. Saudi Pharm. J. 2020, 28, 779-790. [CrossRef] [PubMed]

4. Alam, M.F.; Akhter, M.; Mazumder, B.; Ferdous, A.; Hossain, M.D.; Dafader, N.C.; Ahmed, F.T.; Kundu, S.K.; Taheri, T.; Atique Ullah, A.K.M. Assessment of some heavy metals in selected cosmetics commonly used in Bangladesh and human health risk. J. Anal. Sci. Tech. 2019, 10, 2. [CrossRef]

5. Dwijayanti, E.; Susanti, S. Analysis of Mercury (Hg) in Whitening Cream Distributed in Palu City by Atomic Absorption Spectroscopy (AAS). J. Appl. Chem. Sci. 2018, 5, 430-433. [CrossRef]

6. $\quad$ Ladizinski, B.; Mistry, N.; Kundu, R.V. Widespread Use of Toxic Skin Lightening Compounds: Medical and Psychosocial Aspects. Dermatol. Clin. 2011, 29, 111-123. [CrossRef] [PubMed]

7. World Health Organization. Mercury and Health. 2017. Available online: https://www.who.int/news-room/fact-sheets/detail/ mercury-and-health (accessed on 16 April 2021).

8. Head, K.A. Peripheral neuropathy: Pathogenic mechanisms and alternative therapies. Altern. Med. Rev. $2006,11,294-329$.

9. Robbins, W.B.; Caruso, J.A. Development of Hdyride Generation Method for Atomic Spectroscopy Analysis. Anal. Chem. 1979, 51, 889A. [CrossRef]

10. Lateef, A.M.A.; Mohamed, R.A.; Mahmoud, H.M. Determination of Arsenic (III) and (V) Species in Some Environmental Samples by Atomic Absorption Spectrometry. Adv. Chem. Sci. 2013, 2, 110-113.

11. Moreno, F.N.; Anderson, C.; Stewart, R.; Robinson, B. Analysis of Mercury-Rich Plants and Mine Tailings Using the HydrideGeneration AAS Method. Braz. Arch. Biol. Tech. 2009, 52, 953-960. [CrossRef]

12. Mohammed, E.; Mohammed, T.; Mohammed, A. Optimization of instrument conditions for the analysis for mercury, arsenic, antimony and selenium by atomic absorption spectroscopy. MethodsX 2018, 5, 824-833. [CrossRef] [PubMed]

13. Zhao, Y.; Li, Z.; Ross, A.; Huang, Z.; Chang, W.; Ou-yang, K.; Chen, Y.; Wu, C. Determination of heavy metals in leather and fur by microwave plasma-atomic emission spectrometry. Spectrochim. Acta Part B Atomic Spectros. 2015, 112, 6-9. [CrossRef]

14. Kamala, C.T.; Balaram, V.; Dharmendra, V.; Satyanarayanan, M.; Subramanyam, K.S.V.; Krishnaiah, A. Application of Microwave Plasma Atomic Emission Spectrometry (MP-AES) for environmental monitoring of industrially contaminated sites in Hyderabad City. Environ. Monit. Assess. 2014, 186, 7097-7113. [CrossRef] [PubMed] 
15. Karlsson, S.; Sjoberg, V.; Ogar, A. Comparison of MP AES and ICP-MS for analysis of principal and selected trace elements in nitric acid digests of sunflower (Helianthus annuus). Talanta 2015, 135, 124-132. [CrossRef] [PubMed]

16. Wu, C.; Chen, Y.; Ou-yang, K.; Zhang, Z.; Taylor, C. Analysis of Chinese Herbal Medicines by Microwave Plasma-Atomic Emission Spectrometry (MP-AES) Application Note. Agil. Technol. 2012. Available online: https://hpst.cz/sites/default/files/ oldfiles/5990-9791en-appnote-4100mp-aes-chinesemedicines.pdf (accessed on 2 February 2021).

17. Yang, X.; Pan, J.-C.; Lei, Y.-Q.; Zhou, Q.-L.; Guo, P.-R. Simultaneous Determination of Multiple Elements in Characteristic South China Herbal Medicine by Microwave Plasma Atomic Emission Spectrometry. J. Instrum. Anal. 2015, 34, 227-231. [CrossRef]

18. Alves, V.M.; Muratov, E.N.; Zakharov, A.; Muratov, N.N.; Andrade, C.H.; Tropsha, A. Chemical toxicity prediction for major classes of industrial chemicals: Is it possible to develop universal models covering cosmetics, drugs, and pesticides? Food Chem. Toxicol. 2018, 112, 526-534. [CrossRef] [PubMed]

19. Linsey, M.; Milnes, I. Heavy Metal Analysis of Cosmetics \& Personal Care Products: A Critical and Unavoidable Global Challenge. EURO Cosmet. 2011, 19, 17-19.

20. AOAC International. Appendix F: Guidelines for Standard Method Performance Requirements. 2016. Available online: http:/ / www.eoma.aoac.org/app_f.pdf (accessed on 1 February 2021).

21. Torres, D.P.; Frescura, V.L.A.; Curtius, A.J. Simple mercury fractionation in biological samples by CV AAS following microwaveassisted acid digestion or TMAH pre-treatment. Microchem. J. 2009, 93, 206-210. [CrossRef]

22. Li, Y.; Chen, C.; Li, B.; Sun, J.; Wang, J.; Gao, Y.; Zhao, Y.; Chai, Z. Elimination efficiency of different reagents for the memory effect of mercury using ICP-MS. J. Anal. At. Spectrom. 2006, 21, 94-96. [CrossRef]

23. Valentina, G.; Minkina, V.G.; Stanislav, I.; Shabunya, S.I.; Vladimir, I.; Kalinin, V.I.; Vladimir, V.; Martynenko, V.V.; Alevtina, L.; Smirnova, A.L. Stability of alkaline aqueous solutions of sodium borohydride. Int. J. Hydrogen Energy 2012, 37, $3313-3318$. [CrossRef] 